Archives

\title{
Équivoque, écriture et action : éléments de discussion avec Jean-Pierre Cavaillé
}

Dinah Ribard et Nicolas Schapira

\section{(2) OpenEdition}

Journals

Édition électronique

URL : http://journals.openedition.org/ccrh/257

DOI : $10.4000 /$ ccrh.257

ISSN : $1760-7906$

Éditeur

Centre de recherches historiques - EHESS

Édition imprimée

Date de publication : 1 avril 2004

ISSN : 0990-9141

Référence électronique

Dinah Ribard et Nicolas Schapira, «Équivoque, écriture et action : éléments de discussion avec JeanPierre Cavaillé ", Les Cahiers du Centre de Recherches Historiques [En ligne], 33 | 2004, mis en ligne le 05 septembre 2008, consulté le 10 décembre 2020. URL : http://journals.openedition.org/ccrh/257 ; DOI : https://doi.org/10.4000/ccrh.257

Ce document a été généré automatiquement le 10 décembre 2020.

Article L.111-1 du Code de la propriété intellectuelle. 


\title{
Équivoque, écriture et action : éléments de discussion avec Jean-Pierre Cavaillé
}

\author{
Dinah Ribard et Nicolas Schapira
}

\begin{abstract}
Le nom de la franche France était contredit par une écrasante accumulation d'impôts. La noblesse gémissait, le peuple blasphémait, et les sages accusaient le duc d'Épernon qui était alors favori. Un grand prédicateur du roi aborda ce point en sa

présence, et dit : « Fidèles Parisiens, n'accusez point de vos peines sa Majesté très chrétienne, qui est votre père légitime et véritable. Le coupable est bien connu. Par nom, et Par surnom. » L'auditoire rit beaucoup, et se vengea du même coup ${ }^{1}$.
\end{abstract}

1 Qu'est-ce que raconter une équivoque ? Que fait par exemple Gracián lorsqu'il rapporte ce bon mot d'un prédicateur du temps d'Henri III qui, voulant stigmatiser en présence du roi un de ses favoris, le désigne sans le nommer explicitement? On peut d'abord remarquer que pour le lecteur, et bien que l'anecdote lui soit donnée comme un exemple d'équivoque, il n'y a là nulle équivoque. Gracián ne nous laisse aucun doute sur l'interprétation des paroles du prédicateur : à l'évidence, celui-ci a bien voulu évoquer le favori. Le récit de l'action équivoque, à distance manifeste de cette action, n'est donc pas en lui-même équivoque ; mieux, il va jusqu'à supprimer l'équivoque. Est-il réductible par là à un simple discours théorique, totalement distinct des pratiques et des actions dont il viserait à rendre compte - en l'occurrence, les usages de l'équivoque dans les sociétés modernes? Peut-on au contraire penser une action spécifique des discours sur l'équivoque? Il semble bien qu'au minimum, le récit produise ici une certaine croyance dans les effets de celle-ci, et par là une certaine représentation des rapports, donnés à voir à un public captif, entre le pouvoir et les producteurs de discours, qui sont capables de le défier impunément, mais en même temps de le servir (puisque l'auditoire ne se venge qu'en riant). L'équivoque serait ainsi, dans la description qu'en fournit Gracián, emblématique de la subtilité des intellectuels en face ou au service du pouvoir. 
2 Cet exemple nous oblige à voir que les témoignages (y compris les témoignages contemporains) sur les effets des discours équivoques sont eux-mêmes des discours (et des écrits), et qu'en tant que tels ils ne sont pas obligatoirement les prolongements naturels des actions équivoques qu'ils racontent : ils doivent plutôt être analysés comme d'autres actions. C'est aussi pour cette raison qu'ils ne peuvent pas servir directement, au motif qu'ils appartiendraient à la même époque et manifesteraient une même compréhension des rapports entre la pensée (cachée) et son expression, à l'interprétation de textes équivoques. Il nous semble nécessaire de séparer par méthode deux phénomènes : la prolifération vraiment remarquable des discours sur l'équivoque au XVII ${ }^{\mathrm{e}}$ siècle, et l'existence de textes équivoques, dont il est difficile de savoir s'ils sont plus nombreux ou plus remarquables à cette époque qu'à toute autre. Cette distinction ne vise pas à créer deux ordres de réalité incompatibles (les discours et les actions), mais à se donner les moyens d'analyser pour elle-même la présence massive de ces discours multiformes, comme un phénomène en soi et non comme la simple glose d'une réalité du temps (les conduites équivoques). En retour, on peut ainsi envisager les actions équivoques sous d'autres éclairages que ceux qui sont fournis par le discours sur l'équivoque, ouvrant par là à d'autres interprétations que celles qui sont centrées sur la dialectique de la répression et de la subversion. La socialisation des pratiques équivoques par les récits destinés à en faire des objets de divertissement et peut-être de distinction échappe par exemple à cette dialectique. L'équivoque narrée par Gracián est bien morte : son effet n'est pas de provoquer chez le lecteur l'impression que sa force lui échappe (à la différence de l'équivoque vivante, inquiétante par l'incertitude qu'elle produit), mais de le rassurer dans une complicité partagée - ce qui est bien sûr une action, mais d'une toute autre nature.

3 La mise au jour de deux modalités de l'équivoque textuelle - textes équivoques et textes sur l'équivoque, c'est-à-dire sur l'efficacité des écrits et des discours équivoques - ne peut qu'inviter à retourner la question de l'efficacité - la question de l'action - sur les textes consacrés à l'équivoque eux-mêmes. C'est pourquoi l'enquête sur l'équivoque se révèle un terrain d'observation particulièrement fécond pour une réflexion sur les rapports entre écriture et action.

\section{NOTES}

1. Baltasar Gracián, La Pointe ou l'art du génie, traduction intégrale par Michelle GendreauMassaloux et Pierre Laurens, Paris, L'Âge d'Homme, 1983, p. 241. 


\section{AUTEURS}

DINAH RIBARD

EHESS / CRH-Grihl

NICOLAS SCHAPIRA

Université de Marne-la-Vallée (Grihl) 